Original Article

\title{
The effects of trunk stabilization exercise using a Swiss ball in the absence of visual stimulus on balance in the elderly
}

\author{
Myoung-Kwon KIM, PT, PhD ${ }^{1)}$ \\ 1) Department of Physical Therapy, College of Rehabilitation Sciences, Daegu University: Jillyang, \\ Gyeongsan, Gyeongbuk 712-714, Republic of Korea
}

\begin{abstract}
Purpose] This study was undertaken to investigate the effects of the balance exercises with a Swiss ball on static and dynamic balance abilities in elderly ( $\geq 65$ years) subjects. [Subjects and Methods] Twenty elderly subjects with no relevant orthopedic history of a back condition were selected for trunk stabilization exercises with a Swiss ball (Thera-Band, USA). The subjects performed these trunk stabilization exercises for 20 minutes, five times per week for 4 weeks. The experimental group $(n=10)$ was blindfolded during these balance exercises, while the control group control group $(n=10)$ was not. [Results] The experimental group showed significant improvements in velocity in the evaluation of static balance and in time, total distance, and left/right movement distance in the evaluation of dynamic balance after the intervention, whereas the control group showed significant improvements in time in the evaluation of dynamic balance. A significant intergroup difference was observed after the intervention for velocity gain. [Conclusion] Exercising with a blindfold stimulates other senses by blocking visual information, and hence it enhances improvements in balance ability.

Key words: Trunk stabilization, Balance, Elderly
\end{abstract}

(This article was submitted Feb. 22, 2016, and was accepted Apr. 7, 2016)

\section{INTRODUCTION}

Balance is important for the young and the old, and in the elderly, impaired balance has been associated with reduced functional ability and an increased risk of falls ${ }^{1,2)}$. Balance has been defined as the ability to maintain one's equilibrium when one's center of gravity shifts (dynamic balance), as in walking and running, and when one's center of gravity remains stationary (static balance), as during standing or sitting ${ }^{3)}$. Several neural and biomechanical factors work together to achieve balance, especially the visual, vestibular, and somatosensory systems ${ }^{4}$.

Preventive exercises are most commonly used to reduce the risk in elderly individuals with declining balance ability. In addition, since trunk muscle strength in the elderly is much weaker than limb muscle strength, function improvements in the lumbar region enhance overall body function, improve balance and walking ability, and reduce fall risks ${ }^{5}$.

Swiss ball exercise is used as a rehabilitative tool to correct posture and to treat and prevent pain in the neck and waist, because it can increase muscle strength, endurance, flexibility, and coordination and be used to improve perceptual balancing ability. Trunk stabilization exercises with a Swiss ball can also improve core muscle activation and physical functions, because it enhances balance sense and ability by powerfully stimulating proprioceptors ${ }^{6,7)}$.

Exercises conducted on uneven surfaces, such as a Swiss ball, can generate more activity than exercises on even surfaces and are effective for preventing musculoskeletal damage by improving dynamic balance ${ }^{8,9}$.

According to Seo et al. ${ }^{10)}$, Swiss ball exercises effectively improve balance ability in elderly women, and Song et al. ${ }^{11)}$ reported that Swiss ball and resistance exercises can improve the balance abilities of scoliosis patients.

Corresponding author. Myoung-Kwon Kim (E-mail: skybird-98@hanmail.net)

(C2016 The Society of Physical Therapy Science. Published by IPEC Inc.

This is an open-access article distributed under the terms of the Creative Commons Attribution Non-Commercial No Derivatives (by-nc-nd) License $<$ http://creativecommons.org/licenses/by-nc-nd/4.0/>. 
However, most exercises are performed without blocking vision, which has been shown to have great effects on the ability to balance while standing ${ }^{12}$. However, little research has been conducted to determine the effects of blocking vision on the ability to balance during balance exercises performed with a Swiss ball. Therefore, we investigated the effects of balance exercises with a Swiss ball on static and dynamic balance abilities.

\section{SUBJECTS AND METHODS}

This study was conducted on 20 elderly people living in community homes in D city, South Korea. The study selection criteria applied were as follows: (1) $\geq 65$ years old, (2) no falls within the previous year, (3) the ability to walk independently for more than $10 \mathrm{~m}$ without an ambulatory assistive aid or an assistant, and (4) the absence of any disease that might affect test results. Those with a visual impairment, hearing damage, or a nervous system or vestibular organ problem and those who were unable to understand the nature of the experiment were excluded. All subjects were given information on the study, and all provided written informed consent prior to participation in accordance with the Declaration of Helsinki.

After completing initial assessments, the 20 subjects were randomly assigned to an experimental group $(n=10)$ or a control group $(n=10)$ using preprepared sealed envelopes containing the letters A or B, which indicated the experimental and control groups, respectively. Randomization was conducted by a third party unaware of the study content.

The subjects performed trunk stabilization exercises with a Swiss ball for 20 minutes, five times per week for 4 weeks. Trunk stabilization exercises were carried out using a professional exercise ball (Thera-Band, The Hygenic Corporation, Akron, OH, USA). Ball diameters were chosen on an individual basis so that the subjects' heels could comfortably touch the ground when sitting on the ball. A research assistant demonstrated how to use the ball ${ }^{7)}$.

One set of trunk stabilization exercises was composed of ten repetitions of five different routines. Ten sets were completed in each exercise session with a two-minute break between sets. First, a subject was asked to sit on a ball while lifting one or both arms. Second, the subject sat on the ball with the feet (soles and heels) on the ground while bending the hip and knee joints at 90-degrees, and was then asked to maintain the trunk in an upright position for 20 seconds. Third, the subject performed pelvic tilt (anterior/posterior, left/right) and rotation exercises. Fourth, the subject placed the ball under his/her trunk while in a four-point kneeling position and lifted the arms and legs in the following manner: right arm with left leg and then left arm with right leg consecutively for five seconds. Fifth, with the subject in the prone position, the ball was placed beneath the feet and the hips were lifted for five seconds. During these exercise routines, the experimental group was blindfolded, but the control group was not.

Balance ability was assessed using times taken to perform routines and using distances moved from left to right or forwards and backwards, and balance ability scores were evaluated using a Good Balance System (NCE GB8300, Metitur, Finland). The subjects stood on the foothold of the device and practiced three times to ensure that the test could be performed properly, and three repetitive measurements were averaged ${ }^{13)}$.

Intergroup differences in general characteristics before the intervention were compared using the independent t-test. Intragroup comparisons of variables before and after the intervention were performed using the paired samples t-test. Intergroup comparisons of pre- to post-intervention differences in were performed using the independent t-test. IBM SPSS Statistics ver. 20.0 (IBM Corp., Amonk, NY, USA) was used for statistical analysis, and p values of $<0.05$ were considered significant.

\section{RESULTS}

Twenty subjects (experimental group $=10$, control group=10) completed the experiment.

The experimental group showed significant post-intervention improvements in velocity in examination of static balance and in time, total distance, and left/right movement distance in examination of dynamic balance $(p<0.05)$, whereas the control group achieved significant improvements in time in examination of dynamic balance $(\mathrm{p}<0.05)$. Furthermore, postintervention gains in velocity were significantly greater in the experimental group $(\mathrm{p}<0.05)$ (Tables 1 and 2$)$.

\section{DISCUSSION}

Sustaining balance and stability are essential to avoid falls ${ }^{14)}$. The present study was aimed at examining the effects of trunk stabilization exercises using a Swiss ball whilst blindfolded on balance ability in elderly ( $\geq 65$ years old) subjects. It was found that both the experimental and control groups achieved improvements in dynamic and static balance abilities. In particular, the experimental group achieved a significantly greater increase in static balance ability than the control group. Static balance ability is defined as the ability to maintain one's balance on even surfaces, whereas dynamic balance ability is defined as the ability to maintain one's balance when standing on unstable and/or moving surfaces ${ }^{15)}$. Furthermore, exercising with a blindfold stimulates other senses by blocking visual information, and hence improves balancing ability. In a study conducted by Bonan et al. ${ }^{16)}$, exercise with a blindfold was performed by twenty chronic stroke patients. It was found that balance ability was significantly improved, and this was ascribed to reduced reliance on visual information and forced use of somatosensory and vestibular senses. These results are in agreement with the results of the present study. We found that after four weeks of blindfolded balance exercise, balance ability in our elderly cohort improved significantly more than after four 
Table 1. Post-intervention static balance changes in the experimental and control groups (values are presented as means [standard deviations])

\begin{tabular}{lcccc}
\hline & \multicolumn{2}{c}{ EG } & \multicolumn{2}{c}{ CG } \\
\cline { 2 - 5 } & Pre & Post & Pre & Post \\
\hline Lt/Rt velocity (mm/s) & $5.1 \pm 3.3$ & $4.8 \pm 1.9$ & $4.9 \pm 1.2$ & $4.9 \pm 1.9$ \\
Ant/Post velocity (mm/s) & $6.3 \pm 2.9$ & $6.1 \pm 1.2$ & $7.2 \pm 1.1$ & $7.3 \pm 1.7$ \\
Velocity (mm/s) $^{\mathrm{a}}$ & $18.6 \pm 24.9$ & $11.9 \pm 9.1^{\#}$ & $15.8 \pm 4.3$ & $14.2 \pm 6.1$ \\
Lt/Rt length (mm) & $155.8 \pm 99.5$ & $146.0 \pm 59.6$ & $148.7 \pm 36.8$ & $149.6 \pm 59.8$ \\
Ant/post velocity (mm) & $191.1 \pm 88.0$ & $183.1 \pm 38.1$ & $217.5 \pm 33.4$ & $221.5 \pm 53.0$ \\
\hline
\end{tabular}

EG: experimental group; CG: control group; Ant/post: anterior/posterior; Lt/Rt: left/right

a Significant intergroup difference between the gains achieved, $\mathrm{p}<0.05$

${ }^{\#}$ Significant difference from pre-test $(\mathrm{p}<0.05)$

Table 2. Pre- and post-intervention dynamic balance values in the experimental and control groups (values are presented as means [standard deviations])

\begin{tabular}{lcccc}
\hline & \multicolumn{2}{c}{ EG } & \multicolumn{2}{c}{ CG } \\
\cline { 2 - 5 } & Pre & Post & Pre & Post \\
\hline Time & $16.4 \pm 5.4$ & $10.7 \pm 2.5^{\#}$ & $15.0 \pm 6.8$ & $9.8 \pm 2.0^{\#}$ \\
Total distance (mm) & $1.4 \pm 4.8$ & $1.2 \pm 4.1^{\#}$ & $1.9 \pm 0.5$ & $1.2 \pm 8.3$ \\
Lt/Rt MD (mm) & $937.1 \pm 415.3$ & $782.1 \pm 372.4^{\#}$ & $1,219.1 \pm 1,423.0$ & $806.7 \pm 290.2$ \\
Ant/post MD (mm) & $931.2 \pm 214.7$ & $800.0 \pm 182.6$ & $1,237.4 \pm 793.3$ & $838.3 \pm 167.0$ \\
\hline
\end{tabular}

EG: experimental group; CG: control group; Ant/post MD: anterior/posterior movement distance; Lt/Rt MD: left/ right movement distance

${ }^{\#}$ Significant difference from pre-test $(\mathrm{p}<0.05)$

weeks of non-blindfolded balance exercise.

Some limitations of the present study warrant consideration. First, the small sample size may have biased our results, and thus, our findings cannot be generalized to all elderly. Second, due to the lack of follow-up after the intervention, the durability this intervention could not be determined. Third, functional measurements were not performed to determine whether or not a functional benefit was achieved in terms of the activities of daily living. Therefore, we suggest that additional studies with long-term follow-up assessments should be performed to evaluate the long-term benefits of trunk stabilization exercise without visual information.

\section{ACKNOWLEDGEMENT}

This study was supported by a Daegu University Research Grant (2015).

\section{REFERENCES}

1) Fernie GR, Gryfe CI, Holliday PJ, et al.: The relationship of postural sway in standing to the incidence of falls in geriatric subjects. Age Ageing, 1982, 11: 11-16. [Medline] [CrossRef]

2) Maki BE, Holliday PJ, Topper AK: A prospective study of postural balance and risk of falling in an ambulatory and independent elderly population. J Gerontol, 1994, 49: M72-M84, S4. [Medline] [CrossRef]

3) Gallahue DL, Ozmun JC: Understanding motor development: Infants, children, adolescents, adults, 6th ed. Boston: McGraw-Hill, 2006.

4) Woollacott MH, Shumway-Cook A: Changes in posture control across the life span-a systems approach. Phys Ther, 1990, 70: 799-807. [Medline]

5) Hicks GE, Simonsick EM, Harris TB, et al.: Trunk muscle composition as a predictor of reduced functional capacity in the health, aging and body composition study: the moderating role of back pain. J Gerontol A Biol Sci Med Sci, 2005, 60: 1420-1424. [Medline] [CrossRef]

6) Karatas M, Cetin N, Bayramoglu M, et al.: Trunk muscle strength in relation to balance and functional disability in unihemispheric stroke patients. Am J Phys Med Rehabil, 2004, 83: 81-87. [Medline] [CrossRef]

7) Kim SG, Yong MS, Na SS: The effect of trunk stabilization exercises with a swiss ball on core muscle activation in the elderly. J Phys Ther Sci, 2014, 26: 1473-1474. [Medline] [CrossRef]

8) Lehman GJ, Hoda W, Oliver S: Trunk muscle activity during bridging exercises on and off a Swiss ball. Chiropr Osteopat, 2005, 13: 14. [Medline] [CrossRef]

9) Marshall PW, Murphy BA: Core stability exercises on and off a Swiss ball. Arch Phys Med Rehabil, 2005, 86: 242-249. [Medline] [CrossRef] 
10) Seo BD, Yun YD, Kim HR, et al.: Effect of 12-week swiss ball exercise program on physical fitness and balance ability of elderly woman. J Phys Ther Sci, 2012, 24: 11-15. [CrossRef]

11) Song GB, Kim JJ, Park EC: The effect of Swiss ball exercise and resistance exercise on balancing ability of scoliosis patients. J Phys Ther Sci, 2015, 27: 3879-3882. [Medline] [CrossRef]

12) Jazi SD, Purrajabi F, Movahedi A, et al.: Effect of selected balance exercises on the dynamic balance of children with visual impairments. J Vis Impair Blind, 2012, 106: 466-474.

13) Srivastava A, Taly AB, Gupta A, et al.: Post-stroke balance training: role of force platform with visual feedback technique. J Neurol Sci, 2009, 287: 89-93. [Medline] [CrossRef]

14) Steinman BA, Nguyen AQ, Pynoos J, et al.: Falls-prevention interventions for persons who are blind or visually impaired. Insight. Res Pract Vis Impairment Blindness, 2011, 4: 83-91.

15) Horak FB, Henry SM, Shumway-Cook A: Postural perturbations: new insights for treatment of balance disorders. Phys Ther, 1997, 77: 517-533. [Medline]

16) Bonan IV, Colle FM, Guichard JP, et al.: Reliance on visual information after stroke. Part I: Balance on dynamic posturography. Arch Phys Med Rehabil, 2004, 85: 268-273. [Medline] [CrossRef] 